\title{
ROLE OF APPLE LEAFCURLING MIDGE IN THE SPREAD OF FIRE BLIGHT
}

\author{
S. C. GOUK and R.J. BOYD \\ HortResearch, Ruakura Research Centre, Private Bag 3123, \\ Hamilton, New Zealand
}

\begin{abstract}
The incidence of apple leafcurling midge (Dasineura mali) (ALCM) infestations in association with fire blight (Erwinia amylovora) was monitored in the 1997-98 season. In two blocks of MM106 apple rootstocks, increased fire blight incidence coincided with severe outbreaks of ALCM. Rain did not occur prior to severe outbreaks of both pests. Trees with no ALCM infestation did not develop fire blight, while $61.7 \%$ of those with ALCM infestation subsequently developed fire blight. ALCM damage to leaves predisposed them to fire blight infection. These findings provide the first quantitative evidence that ALCM may be involved in the spread of fire blight.

Keywords: Erwinia amylovora, Dasineura mali, fire blight, apple leaf curling midge.
\end{abstract}

\section{INTRODUCTION}

Fire blight of pipfruit, caused by Erwinia amylovora (Burrill) Winslow et al., is an important bacterial disease in North America, Europe and New Zealand. The pathogen infects different plant parts resulting in blossom blight, shoot blight, canker blight and finally rootstock blight. The shoot blight phase can be damaging and extensive. The long growing season in summer with warm temperatures further favours disease development.

Many insects have been implicated in the dissemination of fire blight (van der Zwet and Beer 1995). Flies and crawling insects that visit cankers have been implicated as one of the agents in the primary spread of fire blight. Bees are an agent in the spread of E. amylovora between flowers (De Wael et al. 1990). Sucking insects such as aphids, plant bugs and leafhoppers are considered important in the infection of vegetative shoots.

In New Zealand, apple leafcurling midge (Dasineura mali Kieffer) (ALCM) has increased in importance in recent years (Tomkins et al. 1994). In the Waikato, ALCM has a high number of generations and can cause substantial shoot damage (Tomkins et al. 1994). The larvae infest the young leaves and shoot tips that are also sites of fire blight infection. ALCM is endemic in Europe and occurs in the United States, but there has been no previous report associating ALCM with fire blight.

In a study of the spatial and temporal spread of shoot blight using apple rootstocks as a model (S.C. Gouk unpubl. data), the incidence of ALCM on the same plants was also recorded. This work indicated that ALCM infestations and fire blight outbreaks were related.

\section{METHODS}

Fire blight incidence in two blocks of one-year old apple rootstocks in the Waikato was monitored in the 1997-98 season. The blocks consisted of 14 rows of MallingMerton MM106 and 6 rows of Malling M793 rootstocks. Each monitored row consisted of 300 trees. The trees were single-stem, some with short laterals at the end of the season. Disease incidence on each tree was monitored at intervals of one to two weeks from December 1997 to April 1998. These one-year old trees did not have flower infections or holdover cankers to complicate studies of shoot blight epidemiology. 
Weather information was obtained from the Orchard 2000 (Beresford and Spink 1992) weather station located at Rukuhia within $10 \mathrm{~km}$ distance from the monitored site.

The relationship between ALCM and fire blight on young terminal shoots was studied by recording the incidence of ALCM damage and fire blight on individual leaves on 151 trees in both blocks. The first fully unrolled leaf at the shoot tip was numbered leaf one and the remaining leaves were numbered in sequence.

Since fire blight incidence was severe in the MM106 trees, the relationship between ALCM infestation and fire blight incidence was studied in more detail. A total of 1605 MM106 trees without fire blight infections but with various stages of ALCM damage were noted on 24 March. The presence or absence of shoot or leaf infection on each tree was determined two weeks later. ALCM damage on each tree was recorded as leaf roll coloration of green, red and/or brown, indicating increasing ages of damage.

\section{RESULTS AND DISCUSSION}

Between December 1997 and mid-March 1998, fire blight incidence increased slightly in both blocks containing 4200 MM106 plants. Between mid-March and the time monitoring stopped in mid-April, there was sharp increase in fire blight incidence (Fig. 1). The increase in fire blight incidence in mid-March corresponded with an observed increase in the level of infestation of ALCM. Young leaves infested with ALCM were initially green and rolled, then turned partially red and eventually brown. The rolled leaves became tattered as the larvae emerged to pupate.

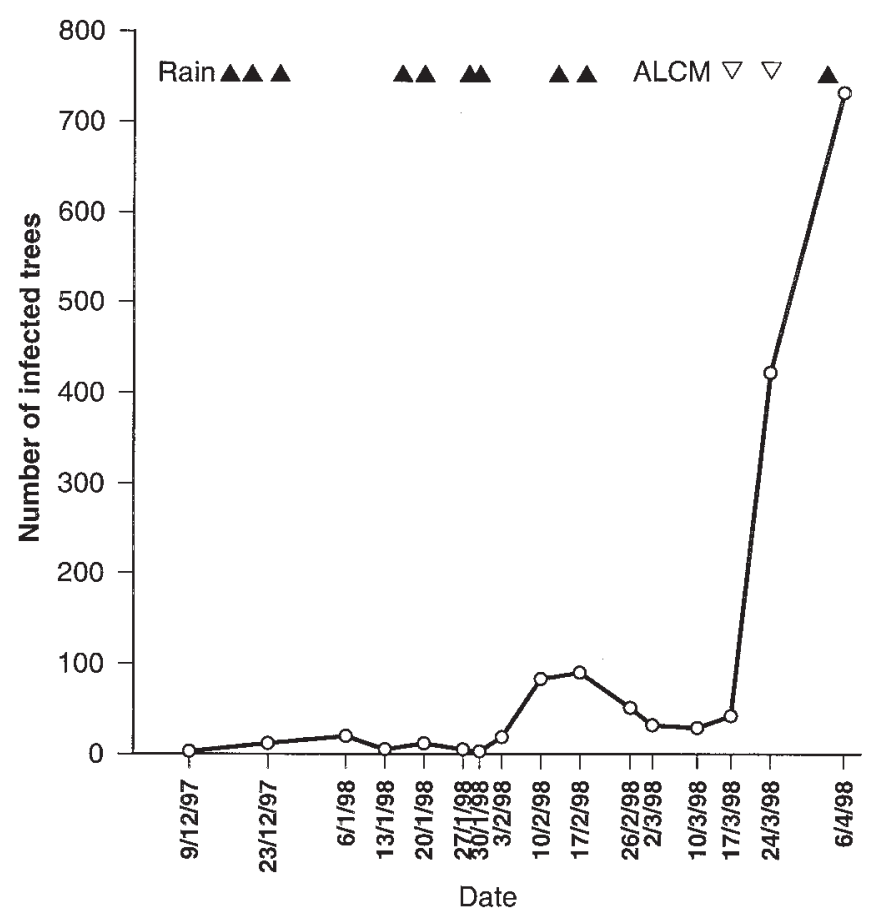

FIGURE 1: Incidence of new fire blight infections at each monitoring date of 4200 MM106 rootstocks, occurrence of rain events, and severe outbreaks of ALCM between December 1997 to April 1998. 
It was initially thought that the increased fire blight incidence may have been related to rain events, since rain splash helps to spread fire blight (van der Zwet and Beer 1995). However, this was not possible since no rain occurred for 6 weeks from 19 February to 1 April. In addition, these trees were not irrigated. The outbreak of ALCM that began in early March was the only significant event during that period. It therefore appeared to be a contributing factor to the rise in fire blight incidence.

Comparison of the position of leaves affected by fire blight and by ALCM showed that they were closely associated. Damage caused by both organisms was most prevalent on young leaves, with less damage found on the older leaves (Fig. 2). It appears likely that ALCM damaged the young leaves, providing the injury necessary for fire blight infections to take place. The importance of tissue injury for entry of E. amylovora has been reported (van der Zwet and Keil 1972). While there is no report on the relationship between ALCM and fire blight in Europe or the United States, a closely related midge, $D$. crataegi, has been reported to encourage fire blight outbreaks on hawthorn in Denmark. This midge causes large wounds that subsequently act as sites for fire blight infection (Thygesen et al. 1973).

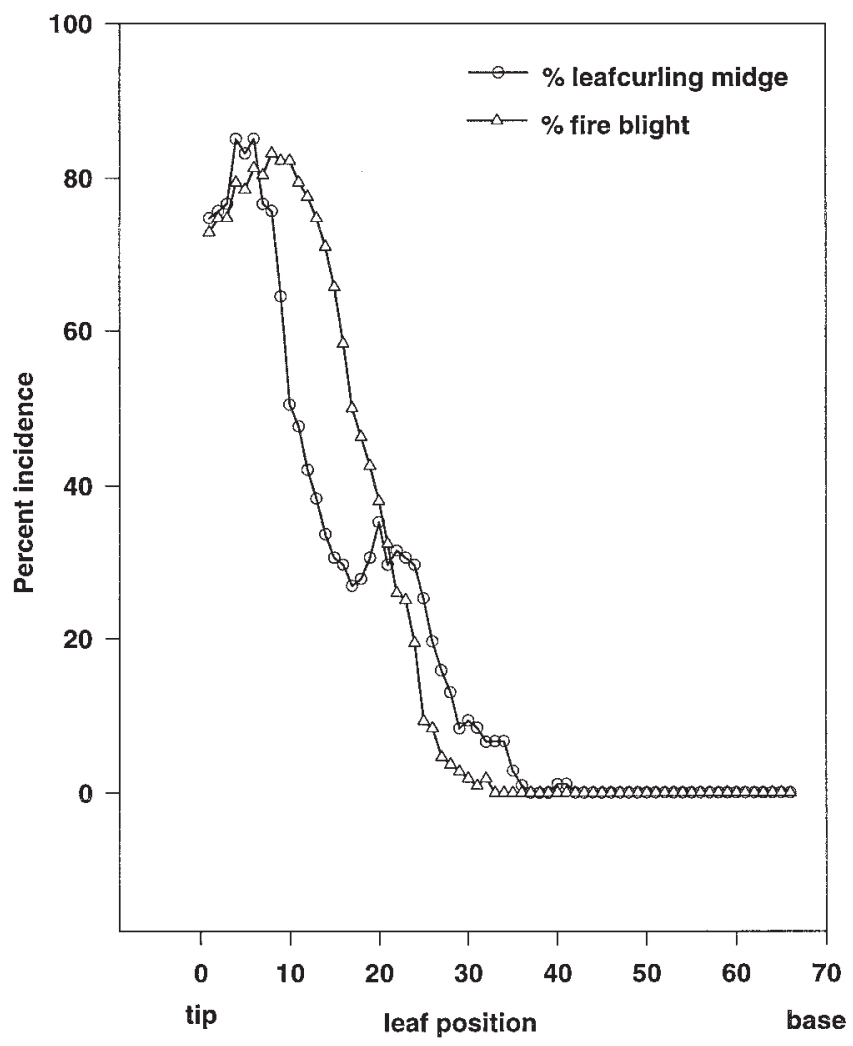

FIGURE 2: Mean incidence of ALCM and fire blight recorded on 4 and 15 April on apple leaves numbered from the first fully unrolled leaf at the tip (leaf 1) towards the base of the plants. 
A total of 1605 trees with no initial fire blight infections and without ALCM infestation were checked for fire blight incidence. The plants that did not have ALCM infestations did not develop fire blight (Fig. 3). Only 6.4\% of the trees more recently infested with ALCM (green stage) developed fire blight. In contrast, a total of $68.9 \%$ of the trees with advanced ALCM infestations (green+red, red+brown, brown stages), subsequently developed fire blight. The data indicated that ALCM infestations provided the damage that encouraged the onset of fire blight. Leaves with more advanced larval infestations had severely damaged tissues that had been exposed to fire blight inoculum for a longer period than more recently infested leaves.

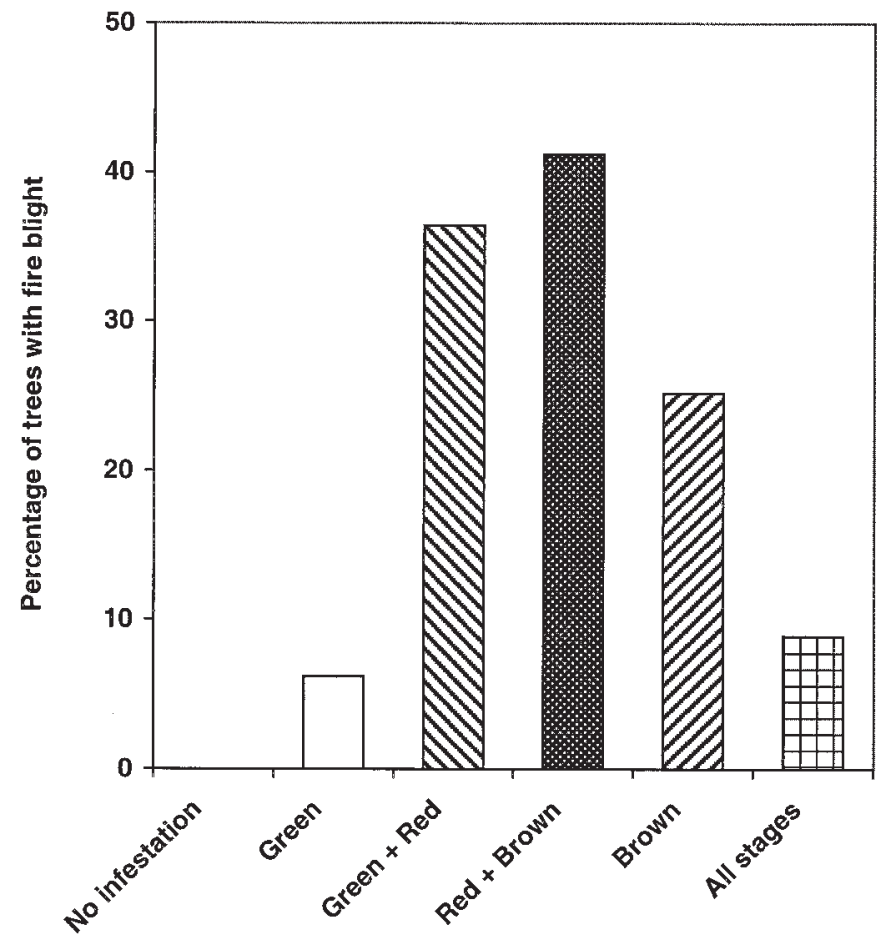

ALCM symptoms

FIGURE 3: The incidence of fire blight that developed on 1605 apple rootstocks that initially had various amounts of ALCM damage but with no fire blight infections. The number of trees in each damage class was: No infestation, 24; Green, 47; Green+Red, 456; Red+Brown, 577; Brown, 354; All stages, 147.

While there was a clear correlation between ALCM infestation and incidence of fire blight, there is currently no evidence to implicate the adult midge as a vector for dissemination of E. amylovora. The adult midges have a short life span of only several days, and therefore have limited time to disseminate bacterial inoculum even if they contact infected tissue. This aspect is a subject for further study. 
The findings suggest effective control of ALCM may help to reduce fire blight outbreaks. This is particularly important during shoot extension in orchards or nursery blocks where fire blight inoculum is present. With the higher incidence of ALCM in New Zealand orchards recently, it would seem advisable to include ALCM control in fire blight management strategies. The findings also have implication for control of fire blight on pears as they suffer from a similar damage caused by pear leafcurling midge (D. pyri).

\section{ACKNOWLEDGEMENTS}

The authors thank T. Eden for technical assistance, B. Dow for data analysis, A. Tomkins and C. Thomson for advice on ALCM, and the grower for use of the trees in this study.

\section{REFERENCES}

Beresford, R.M. and Spink, M., 1992. A national disease forecasting system for apple black spot (Venturia inaequalis) in New Zealand. Acta Horticulturae 313: 285-296.

De Wael L., De Greef, M. and Van Laere, O., 1990. The honeybee fireblight relation. Apiacta XXV: 111-117.

Thygesen, T., Esbjerg, P. and Eiberg, H., 1973. Fireblight transmission by insects. Tidsskrift-for-Planteavl 77: 324-336.

Tomkins, A.R., Wilson, D.J., Hutchings, S.O. and June, S., 1994. A survey of apple leafcurling midge (Dasyneura mali) in Waikato orchards. Proc. 47th N.Z. Plant Prot. Conf.: 346-349.

Van der Zwet, T. and Keil, H.L., 1972. Importance of pear tissue injury to infection by Erwinia amylovora and control with streptomycin. Can. J. Micro 18:839-900.

Van der Zwet, T. and Beer, S.V., 1995. Fire Blight - its Nature, Prevention and Control. A practical guide to integrated disease management. USDA. Agriculture Information Bulletin No. 631.97 pp. 